\title{
Characterization of the caprolactam degradation pathway in Pseudomonas jessenii using mass spectrometry-based proteomics
}

\author{
Marleen Otzen ${ }^{1} \cdot$ Cyntia Palacio $^{1} \cdot$ Dick B. Janssen $^{1}$ (B) \\ Received: 1 December 2017 / Revised: 21 March 2018 / Accepted: 23 March 2018 / Published online: 31 May 2018 \\ (C) The Author(s) 2018
}

\begin{abstract}
Some bacterial cultures are capable of growth on caprolactam as sole carbon and nitrogen source, but the enzymes of the catabolic pathway have not been described. We isolated a caprolactam-degrading strain of Pseudomonas jessenii from soil and identified proteins and genes putatively involved in caprolactam metabolism using quantitative mass spectrometry-based proteomics. This led to the discovery of a caprolactamase and an aminotransferase that are involved in the initial steps of caprolactam conversion. Additionally, various proteins were identified that likely are involved in later steps of the pathway. The caprolactamase consists of two subunits and demonstrated high sequence identity to the 5-oxoprolinases. Escherichia coli cells expressing this caprolactamase did not convert 5-oxoproline but were able to hydrolyze caprolactam to form 6-aminocaproic acid in an ATP-dependent manner. Characterization of the aminotransferase revealed that the enzyme deaminates 6-aminocaproic acid to produce 6-oxohexanoate with pyruvate as amino acceptor. The amino acid sequence of the aminotransferase showed high similarity to subgroup II $\omega$ aminotransferases of the PLP-fold type I proteins. Finally, analyses of the genome sequence revealed the presence of a caprolactam catabolism gene cluster comprising a set of genes involved in the conversion of caprolactam to adipate.
\end{abstract}

Keywords Caprolactam $\cdot$ Caprolactamase $\cdot$ Omega aminotransferase $\cdot$ Mass spectrometry $\cdot$ Proteomics $\cdot$ Pseudomonas jessenii

\section{Introduction}

Caprolactam is a large-volume industrial compound mainly used in the production of Nylon 6, a versatile synthetic polymer applied in fabrics, utensils, mechanical parts, etc. Synthesis of Nylon 6 is achieved by ring-opening polymerization of caprolactam at high temperatures. During this process, several side products are generated, including 6aminocaproic acid (6-aminohexanoic acid (6-ACA)) unreacted monomers, as well as dimers, cyclic dimers, and oligomers of 6-ACA. Caprolactam and these by-products are present as contaminants in waste water of nylon production

Electronic supplementary material The online version of this article (https://doi.org/10.1007/s00253-018-9073-7) contains supplementary material, which is available to authorized users.

Dick B. Janssen

d.b.janssen@rug.nl

1 Biochemical Laboratory, Groningen Biomolecular Sciences and Biotechnology Institute, University of Groningen, Nijenborgh 4, 9747 AG Groningen, The Netherlands plants (Fortmann and Rosenberg 1984; Kalinová et al. 2014, 2016). The toxic nature of these chemicals, including mutagenic effects and plant growth inhibition, has been shown in different studies (Sheldon 1989; Vogel 1989).

Several microorganisms are able to degrade caprolactam and/or these by-products, including strains of Pseudomonas, Alcaligenes, and Acinetobacter (Kulkarni and Kanekar 1998; Rajoo et al. 2013; Baxi and Shah 2002). Previously, a caprolactam degradation pathway was proposed (Caspi et al. 2014). It starts with a caprolactam-ring cleavage to form 6-ACA, followed by the deamination to 6-oxohexanoate and subsequent oxidation to yield adipate. Adipate can be further converted via $\beta$-oxidation reactions of the fatty acid metabolism pathway. Whereas this pathway seems straightforward, information about the proteins involved in bacterial caprolactam degradation is rare. At first sight, one would expect a hydrolytic enzyme involved in lactam ring opening. The conversion of the related D,L- $\alpha$-amino- $\varepsilon$-caprolactam by a combination of a racemase and a L-amino acid lactam hydrolase to yield Llysine has been described (Payoungkiattikun et al. 2017; Fukumura et al. 1978; Ahmed et al. 1982, 1986). Additionally, a putative hydrolase and aminotransferase have been reported for caprolactam metabolism. Recent work 
suggests that a dehydrogenase may oxidize 6-oxohexanoate to adipate in Arthrobacter sp. KI72 and in Acinetobacter sp. NCIMB 9871. Subsequently, an aminotransferase might catalyze the conversion of 6-ACA to 6-oxohexanoate in the cell (Takehara et al. 2018; Iwaki et al. 1999).

The environmental relevance of caprolactam, and the importance to understand the biodegradation pathway of this synthetic compound, prompted us to investigate the biochemistry of the early degradation steps. In this paper, we describe a newly isolated caprolactam degrading strain of Pseudomonas jessenii. To investigate the pathway, and identify the enzymes involved, we used label-free quantitative mass spectrometrybased proteomics (van der van der Wal and Demmers 2015; Fabre et al. 2014; Wasinger et al. 2013). From the various caprolactam-induced proteins, we further examined an unexpected ATP-dependent caprolactamase that forms 6-ACA and a class-II omega-aminotransferase that converts 6-ACA to 6oxohexanoate. The activities of the enzymes were examined with heterologously expressed proteins. Furthermore, a caprolactam degradation gene cluster containing all genes for the conversion of caprolactam to adipate was detected by genome sequencing.

\section{Materials and methods}

\section{Growth conditions}

Escherichia coli C41 (DE3) cells (Lucigen, Halle-Zoersel, Belgium) were grown at $37{ }^{\circ} \mathrm{C}$ in an $\mathrm{LB}$ medium (Sambrook et al. 2001). When required, ampicillin $(50 \mu \mathrm{g} /$ $\mathrm{mL}$ ) was added. The caprolactam-degrader P. jessenii GO3 was cultured at $30{ }^{\circ} \mathrm{C}$ in nitrogen-free minimal medium (MM) (Gabor et al. 2004), supplemented with caprolactam ( $4 \mathrm{mM}$ ) as carbon and nitrogen source. For the preparation of agar plates, the medium was supplemented with $2 \%$ agar or $1.6 \% \mathrm{H}_{2} \mathrm{O}$-rinsed agarose.

To determine the caprolactam tolerance of $P$. jessenii GO3, cells were precultured in MM supplemented with $0.1 \%$ caprolactam at $30{ }^{\circ} \mathrm{C}$. Cells from these precultures were diluted 50- to 100 -fold in $200 \mu \mathrm{L}$ fresh medium supplemented with varying concentrations of caprolactam (0.05 to $1.2 \%)$. Subsequently, growth was monitored by measuring the absorbance at $\mathrm{OD}_{600}$ using a microplate spectrophotometer (PowerWave, BioTek, Winooski, VT, USA).

\section{Enrichment of caprolactam-degrading bacteria}

For the isolation of bacterial strains, $1 \mathrm{~g}$ of residential grassland soil from Groningen (The Netherlands) was used to inoculate $50 \mathrm{~mL}$ nitrogen-free $\mathrm{MM}$ supplemented with $0.2 \%$ glucose and $0.5 \mathrm{mM}$ caprolactam as sole carbon and nitrogen source. Cultures were incubated for 7 days in an orbital shaker at $30{ }^{\circ} \mathrm{C}$. Subsequently, cells were transferred two times to fresh liquid medium after which pure cultures were isolated on MM agarose plates supplemented with $0.2 \%$ glucose and $0.5 \mathrm{mM}$ caprolactam. To confirm growth of the resulting pure cultures on caprolactam, cells were reinoculated in selective liquid MM. Identification of isolated organisms was based on the analyses of the $16 \mathrm{~S}$ rRNA gene sequence, received from the partial genome sequence obtained in this study, using the online EzTaxon database (Chun et al. 2007). P. jessenii strain GO3 is deposited at DSMZ (Braunschweig, Germany) under accession number DSM 106008.

\section{Genome sequencing and annotation}

In order to obtain a partial genome sequence, total DNA from $P$. jessenii GO3 cells was isolated essentially as described previously (Poelarends et al. 1998; Sambrook et al. 2001). The resulting genomic DNA was subjected to paired end sequencing by BaseClear BV (Leiden, The Netherlands). The genome sequencing was done using a HiSeq2500 system (Illumina Inc., Eindhoven, The Netherlands). Sequencing of the GO3 genome yielded 1.7 million reads of $\sim 100 \mathrm{bp}$ in length. These were assembled by BaseClear, using the CLC Genomics Workbench version 7.0.4 (Qiagen, Venlo, The Netherlands), resulting in 1274 contigs with a total length of 7 mega base pairs $(\mathrm{Mb})$. This whole genome project has been deposited at DDBJ/ENA/GenBank under the accession PDLL00000000. The version described in this paper is PDLL01000000. Subsequently, all generated contigs were used for automated annotation using the RAST server (Aziz et al. 2008).

\section{Molecular techniques}

Standard recombinant DNA techniques were performed essentially as described previously (Sambrook et al. 2001). Restriction enzymes and polymerase were used according to the instructions of the supplier (New England Biolabs, Ipswich, MA, USA). Primers used in this study are listed in Table 1.

\section{Plasmid constructions}

For the purification of a 6-ACA aminotransferase (PjAT), plasmid pET-PjAT was constructed containing an in-frame fusion of the PjAT-encoding gene to a hexahistidine tag, behind the T7 promoter region. For this purpose, the PjAT gene was amplified using $P$. jessenii GO3 chromosomal DNA and primers ATfw and ATrev. The resulting 1419 base pair product was then digested with $N d e \mathrm{I} / E c o \mathrm{RI}$ and ligated into $\mathrm{NdeI} /$ EcoRI-digested pET20b ${ }^{+}$(Novagen-Merck, Amsterdam, The Netherlands). 
Table 1 Primers used

$\begin{array}{ll}\text { ATfw } & \text { TTCCTTCTCTAGAATGAACCAGTCAGTATCCTCGC } \\ \text { ATrev } & \text { TTCCTGAATTCTTAATGATGATGATGATGATGGCCGCCCGGACCAACCCACTGAGTGGTGTC } \\ \text { OPfw } & \text { ATCAAGCTTAATGAACACAGTAGACCCGATC } \\ \text { OPrev } & \text { AAGGAAAAAAGCGGCCGCTCAATGACCGGGAGTCAGTTC }\end{array}$

For the expression of caprolactamase subunits $\alpha$ and $\beta$, plasmid pET-OP was constructed containing both genes, behind the T7 promoter region. Since both genes are likely located in one operon, they were amplified together using $P$. jessenii GO3 chromosomal DNA and primers OPfw and OPrev. The resulting 3871 base pair fragment was then digested using HindIII and NotI and ligated into HindIII/ NotI-digested pET $20 \mathrm{~b}^{+}$

\section{Proteomics by mass spectrometry}

Pseudomonas jessenii GO3 cells were cultured in $50 \mathrm{~mL} \mathrm{MM}$ supplemented with $0.2 \%$ glucose and $5 \mathrm{mM}\left(\mathrm{NH}_{4}\right)_{2} \mathrm{SO}_{4}$ or with $4 \mathrm{mM}$ caprolactam. When the culture reached the late exponential growth phase, cells were harvested by centrifugation at $3000 \times g$ for $15 \mathrm{~min}$. Cell pellets were washed once with $50 \mathrm{mM}$ potassium phosphate buffer, $\mathrm{pH} \mathrm{7.8,} \mathrm{and} \mathrm{stored} \mathrm{at} \mathrm{-}$ $20{ }^{\circ} \mathrm{C}$ prior to use.

For mass spectrometry, cell pellets were resuspended in $50 \mathrm{mM}$ potassium phosphate buffer, $\mathrm{pH} \mathrm{7.8,} \mathrm{and} \mathrm{lysed} \mathrm{using}$ a Vibra Cell sonicator (Sonics, Newtown, CT, USA) at $0{ }^{\circ} \mathrm{C}$. To remove unbroken cells and cell debris, the samples were centrifuged at $17,000 \times \mathrm{g}$ for $60 \mathrm{~min}$ at $4{ }^{\circ} \mathrm{C}$. Soluble protein was precipitated by the addition of $20 \%$ trichloroacetic acid (TCA). After incubating the samples for $1 \mathrm{~h}$ on ice, samples were centrifuged at $17,000 \times \mathrm{g}$ for $30 \mathrm{~min}$ at $4{ }^{\circ} \mathrm{C}$. Protein pellets were washed with ice-cold acetone to remove residual TCA. Dry protein extracts were then resuspended in $50 \mu \mathrm{L}$ $50 \mathrm{mM} \mathrm{NaOH}$. Reduction of the samples was performed with $5 \mu \mathrm{L}$ of $500 \mathrm{mM}$ dithiothreitol (DTT) in $350 \mu \mathrm{L} 100 \mathrm{mM}$ $\mathrm{NH}_{4} \mathrm{HCO}_{3}$ for $30 \mathrm{~min}$ at $25^{\circ} \mathrm{C}$, followed by derivatization of sulfhydryls by $30 \mathrm{~min}$ incubation at room temperature with $10 \mu \mathrm{L}$ of $550 \mathrm{mM}$ iodoacetamide. Trypsin digestion was performed overnight at $37^{\circ} \mathrm{C}$ by addition of $4 \mu \mathrm{g}$ trypsin gold (mass spectrometry grade, Promega (Leiden, The Netherlands)), followed by a second trypsin digestion for $3 \mathrm{~h}$ at $37{ }^{\circ} \mathrm{C}$ using $1 \mu \mathrm{g}$ trypsin gold. Samples were prepared for injection by addition of $2.5 \%$ formic acid.

For LC-MS, peptides were first trapped on a precolumn (EASY-Column C18, $100 \mu \mathrm{m} \times 20 \mathrm{~mm}, 5 \mu \mathrm{m}$ particle size, Thermo Scientific, Ermelo, The Netherlands) and separated on a capillary column (C18 PepMap 300, $75 \mu \mathrm{m} \times 100 \mathrm{~mm}$, 3 - $\mu \mathrm{m}$ particle size, Thermo Scientific) mounted on a Proxeon Easy-nLCII system (Thermo Scientific). Solutions of $0.1 \%$ formic acid in water, and $0.1 \%$ formic acid in $100 \%$ acetonitrile, were used as the mobile phases. A gradient from 5 to $40 \%$ acetonitrile was performed at a flow rate of $300 \mathrm{~nL} /$ min. Eluted peptides were analyzed using a linear ion trap Orbitrap hybrid mass spectrometer (LTQ-Orbitrap XL, Thermo Scientific). MS scans were acquired in the range from 300 to $2000 \mathrm{~m} / \mathrm{z}$. The five most intense ions per scan were selected for MS/MS fragmentation (35\% normalized collision energy) and detected in the linear ion trap.

Peak lists were obtained from raw data files using Proteome Discoverer (version 1.1, Thermo Fisher Scientific). Mascot (version 2.1, Matrix Science, London, UK) was used for searching against the annotated $P$. jessenii GO3 genomic DNA sequence. Peptide tolerance was set to $10 \mathrm{ppm}$ and the fragment ion tolerance to $2.0 \mathrm{Da}$, using semitrypsin as protease specificity and allowing for up to two missed cleavages. Oxidation of methionine residues, deamidation of asparagine and glutamine, and $S$ carboamidomethylation of cysteines were specified as variable modifications. The MS/MS-based peptide and protein identifications were further validated with the program Scaffold (version 4.6.1, Proteome Software Inc., Portland, OR, USA). Peptide identifications were accepted when the probability was greater than $95 \%$. Protein identifications were based on at least two unique peptides identified by MS/MS, each with a confidence of identification probability higher than $99 \%$.

For each growth condition, at least two replicates of two independent cultures were analyzed. Normalized intensitybased absolute quantification (iBAQ) values from Scaffold were used as a measure for the abundance of the identified proteins. Average iBAQ values were calculated for the different samples and subsequently $\log 2$ transformed. In case the protein was not detected, the log2-transformed iBAQ value was manually set to $8.5,2.5$-fold below the approximate limit of detection. The effect of growth conditions on specific protein amounts was calculated by dividing the average $\log 2$ iBAQ value for each protein in extracts from caprolactamgrown cells by the corresponding $\mathrm{BAAQ}$ value in protein extracts from control cells. A protein was considered upregulated when the $\log 2$-fold ratio was more than two and downregulated when the $\log 2$-fold ratio was less than 0.5 .

The mass spectrometry proteomics data have been deposited to the ProteomeXchange Consortium via the PRIDE (Vizcaíno et al. 2016) partner repository with the dataset identifier PXD008544 and https://doi.org/10.6019/PXD008544. 


\section{Expression and purification}

The aminotransferase PjAT and caprolactamase were both produced in $E$. coli $\mathrm{C} 41$ cells under control of the $\mathrm{T} 7$ promoter. PjAT was expressed and purified as previously described for related aminotransferases (Palacio et al. 2016).

For the expression of the $\alpha$ and $\beta$ subunits of caprolactamase, $0.5 \mathrm{~mL}$ of an overnight grown LB culture of pET-OP transformed cells was transferred to $50 \mathrm{~mL}$ autoinduction medium (ForMedium) containing ampicillin and incubated for $48 \mathrm{~h}$ in a rotary shaker at $17^{\circ} \mathrm{C}$. To prepare cell-free extracts, cells were washed in buffer A $(50 \mathrm{mM}$ ammonium bicarbonate, $\mathrm{pH} 8.5,10 \mathrm{mM} \mathrm{MgCl}_{2}$ ), resuspended in buffer A, and lysed using a Sonics Vibra Cell sonicator at $0{ }^{\circ} \mathrm{C}$. To remove unbroken cells and cell debris, the samples were centrifuged at $17,000 \times \mathrm{g}$ for $30 \mathrm{~min}$.

\section{Enzyme kinetics}

To analyze aminotransferase activity in cell-free extracts, reactions were followed using HPLC analyses. Cell-free extracts were prepared in $50 \mathrm{mM}$ potassium phosphate buffer (pH 8) containing $0.3 \mathrm{mM}$ pyridoxal 5'-phosphate (PLP). Standard reaction mixtures contained $50 \mathrm{mM}$ potassium phosphate buffer ( $\mathrm{pH} 8$ ), $2 \mathrm{mM}$ amine donor (pyruvate or $\alpha$ ketoglutarate), $5 \mathrm{mM}$ 6-ACA, $0.3 \mathrm{mM}$ PLP, and cell-free extract, in a total volume of $300 \mu \mathrm{L}$. Reactions were carried out at $28{ }^{\circ} \mathrm{C}$. With different time intervals, $50 \mu \mathrm{L}$ samples were taken and quenched by the addition of $50 \mu \mathrm{L} 2 \mathrm{M} \mathrm{HCl}$. After incubating the samples for $10 \mathrm{~min}$ on ice, samples were centrifuged for $10 \mathrm{~min}$ at $17,000 \times g$ and neutralized using $100 \mu \mathrm{L}$ $1 \mathrm{M} \mathrm{NaOH}$. Amino acids (6-ACA, alanine, glutamate) in the reaction mixtures were quantified by precolumn $o$ phthalaldehyde (OPA) derivatization and subsequent HPLC analyses. To this purpose, $10-\mu \mathrm{L}$ sample was mixed with $40 \mu \mathrm{L} 0.4 \mathrm{M}$ boric acid ( $\mathrm{pH}$ 9.7) and $10 \mu \mathrm{L}$ OPA solution (Fisher Scientific) and incubated for $20 \mathrm{~min}$ at $30^{\circ} \mathrm{C}$. Then, $3 \mu \mathrm{L}$ of the reaction sample were injected by an autosampler and analyzed by HPLC using a C18 OPA Adsorbosphere column connected to a Jasco FP-920 detector (excitation $350 \mathrm{~nm}$; emission $450 \mathrm{~nm}$ ). Compounds were eluted using a linear gradient (eluent $\mathrm{A}, 20 \mathrm{mM}$ sodium acetate, $\mathrm{pH} 7.2$, $0.5 \%$ (vol/ $/ \mathrm{vol}$ ) tetrahydrofuran, $0.018 \%$ (vol $/ \mathrm{vol}$ ) TEA and eluent B, $90 \%$ acetonitrile) at a flow rate of $0.5 \mathrm{~mL} / \mathrm{min}$.

The activity of purified PjAT with pyruvate as the amine acceptor was estimated by coupling the reaction to alanine dehydrogenase and measuring the increase in NADH absorbance that occurs as a result of oxidative deamination of the produced alanine. Since pyruvate is a competitive inhibitor of alanine dehydrogenase, low pyruvate concentrations were used to minimize the lag time of the reaction. The concentration of alanine dehydrogenase in the assays was in excess (5 units $/ \mathrm{mL}$ ), to give aminotransferase-dependent velocities.
Standard reaction mixtures contained $100 \mathrm{mM}$ potassium phosphate buffer $(\mathrm{pH} 8), 5 \mathrm{U} / \mathrm{mL}$ alanine dehydrogenase, $2 \mathrm{mM} \mathrm{NAD}^{+}, 0.05 \mathrm{mM}$ PLP, $2 \mathrm{mM}$ substrate, $0.2 \mathrm{mM}$ pyruvate, and varying concentrations of enzyme in a total volume of $300 \mu \mathrm{L}$ in flat-bottom 96 -well microtiter plates. Reactions were carried out at $30^{\circ} \mathrm{C}$ and analyzed using a microtiter plate reader (Synergy Mx Microplate Reader, BioTek Instruments, Bad Friedrichshall, Germany). Reaction mixtures lacking pyruvate $(150 \mu \mathrm{L})$ were prewarmed before the reaction was initiated by the addition of $150-\mu \mathrm{L}$ pyruvate solution. Each reaction was analyzed in triplicate. Initial rates were used to determine specific activities in units per $\mathrm{mg}$ protein $(\mu \mathrm{mol} / \mathrm{min} / \mathrm{mg})$. Protein content was determined using the Bradford method, with bovine serum albumin as the standard.

The amination of 6-oxohexanoate with alanine as donor was also followed by coupling to alanine dehydrogenase. The reaction mixtures contained $100 \mathrm{mM}$ potassium phosphate buffer ( $\mathrm{pH} 8$ ), $2 \mathrm{mM}$ substrate, $0.1 \mathrm{mM} \mathrm{NADH,}$ $0.05 \mathrm{mM}$ PLP, $8 \mathrm{U} / \mathrm{mL}$ alanine dehydrogenase, $5 \mathrm{mM}$ ammonium bicarbonate, $5 \mathrm{mM}$ L-alanine, and varying concentrations of enzyme in a total volume of $300 \mu \mathrm{L}$. Reactions were initiated by addition of $150 \mu \mathrm{L}$ of L-Ala and carried out as described previously. Conversion was followed by measuring NADH depletion at $340 \mathrm{~nm}$.

Caprolactamase activity was determined by analyzing reaction mixtures using an Acquity TQD mass spectrometer (Waters, Etten-Leur, The Netherlands). Standard reaction mixtures contained $2 \mathrm{mM}$ substrate (caprolactam or 5oxoproline), $5 \mathrm{mM}$ ATP, $10 \mathrm{mM} \mathrm{MgCl}_{2}$, and cell-free extract, in $50 \mathrm{mM}$ ammonium bicarbonate, $\mathrm{pH}$ 8.5. Samples were taken and quenched by the addition of $2 \%$ formic acid. Separation of the reaction content was performed by UPLC using a Waters Acquity UPLC HSS T3 Column $(1.8 \mu \mathrm{m}$, $2.1 \times 150 \mathrm{~mm}$ ) and a linear gradient (eluent $\mathrm{A}$ : water, $0.1 \%$ formic acid; eluent B: 100 acetonitrile, $0.1 \%$ formic acid). The samples were analyzed in positive ion mode. To determine substrate reduction and product formation, multiple reaction monitoring (MRM) was performed, measuring the following fragments: caprolactam $\mathrm{m} / \mathrm{z}=96$; 6 -ACA $\mathrm{m} / \mathrm{z}=114 ; 5$ oxoproline $m / z=84$; glutamate $m / z=102$.

\section{Results}

\section{Isolation of bacterial strains using caprolactam as a sole nitrogen source}

In order to isolate a bacterial strain possessing a caprolactam metabolism pathway, soil microorganisms were enriched for the ability to grow on caprolactam as sole nitrogen source. A pure culture was obtained by repeated transfer to fresh medium plates. The bacterial strain that was growing best on 
selective medium was used to study caprolactam metabolism in detail and was designated strain $\mathrm{GO} 3$.

Growth analyses revealed that strain $\mathrm{GO} 3$ was able to use caprolactam both as a sole nitrogen and carbon source. Interestingly, 6-aminohexanoic acid (6-ACA), a described intermediate in caprolactam degradation (Caspi et al. 2014), was not a possible growth substrate for this strain. In mineral medium (MM) supplemented with $0.05 \%$ caprolactam as sole carbon and nitrogen source, the calculated $\mu_{\max }$ was $0.37 \mathrm{~h}^{-1}$. Growth analyses using different concentrations of caprolactam in MM revealed that the $\mu_{\max }$ is reduced by higher concentration of caprolactam, with a calculated critical caprolactam concentration of $0.46 \%$ (Fig. 1).

\section{Draft genome sequence}

After paired end sequencing of the genomic DNA from strain GO3, genome assembly resulted in 1274 contigs (N50: $10,682 \mathrm{bp}$ ), covering $6,993,317 \mathrm{bp}$. The GC content is $60 \%$ with 6231 predicted coding sequences. Among these predicted genes, 4754 were assigned a predicted function (76\%). Furthermore, 3 rRNA and 61 tRNA genes were identified in the draft genome.

Analyses of the 16S rRNA gene revealed that the organism is a Pseudomonas species closely related to P. jessenii CIP 105274 (99.5\% identity). The draft genome was compared to related Pseudomonas species of which the complete sequence is published, including the caprolactam-degrading organism Pseudomonas mosselii SJ10 (Park et al. 2014) (Table 2). Previous studies showed that in other caprolactam-utilizing Pseudomonas strains, the genes involved in caprolactam metabolism are plasmid localized (Boronin et al. 1984). Using gel electrophoresis of DNA extracts, we did not find a plasmid in P. jessenii GO3 (data not shown), suggesting a chromosomal location of the catabolic genes.

\section{Identification of caprolactam degradation enzymes}

A hypothetical caprolactam degradation pathway (Esikova et al. 2012) involves two unidentified enzymes: the ringcleavage enzyme, presumably a hydrolase, and the enzyme involved in the deamination reaction, which could be an aminotransferase, an oxidase, or an amine dehydrogenase, all three producing an $\omega$-ketoacid. To identify the enzymes involved in the pathway, the $P$. jessenii GO3 proteome was examined for caprolactam-induced proteins. To this purpose, $P$. jessenii cells were grown in minimal medium supplemented with caprolactam $(4 \mathrm{mM})$, or glucose plus ammonium sulfate. Cell-free extracts were prepared from both cultures and subjected to quantitative proteome analysis using a label-free approach.

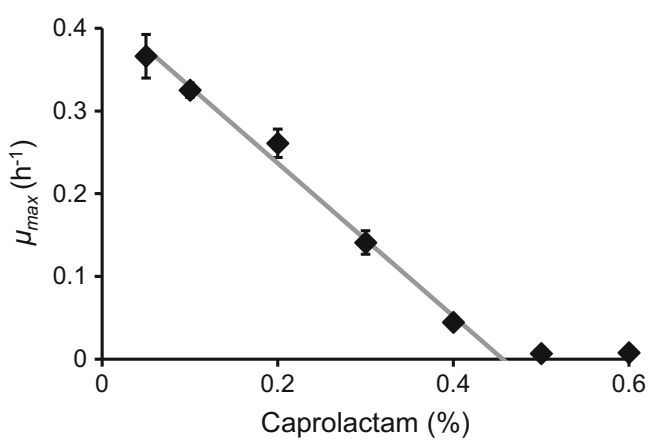

Fig. 1 Specific growth rates of $P$. jessenii GO3 in media supplemented with different concentrations of caprolactam

A total of 137 different proteins were identified in the combined independent replicate experiments, corresponding to $2.2 \%$ of the predicted P. jessenii proteome. Among these, 109 proteins were identified in both experiments and were subjected to further bioinformatic analysis (Fig. 2a). Seventeen of these proteins showed at least a 2-fold increase in $\log 2$ protein abundance in the caprolactam-grown cells as compared to the glucose cultures (Fig. 2b, Table 2; Supporting information Table S1 and Table S2). Interestingly, some proteins are highly induced on caprolactam, while others are just above the level of detection (LOD 21, Fig. 2c). Conversely, in glucose-grown cells, these proteins were below the level of detection (iBAQ $<21$, data not shown).

\section{Hypothetical caprolactam degradation pathway}

Based on the identified caprolactam-induced proteins (Table 3), in combination with previous data (Esikova et al. 2012), a complete putative $P$. jessenii caprolactam degradation pathway was built, including all enzymes that play a role in the pathway (Fig. 3). To enable growth on caprolactam as sole carbon and nitrogen source, an active uptake of caprolactam might be needed, which may be dependent on $\mathrm{ABC}$ transporter proteins. Four $\mathrm{ABC}$ transporter substrate binding proteins are significantly induced during growth on caprolactam, including ORF1056, ORF3044, ORF1114, and ORF2532 (Table 3). Database searches demonstrated homology to various ABC transporters, including the spermidine/putrescine binding proteins (ORF1056 and ORF3044), the branched chain amino acid binding proteins (ORF1114), and the amino acid binding proteins (ORF2532). Interestingly, ORF1114 and ORF2532 were predominantly induced when the cells were grown on caprolactam as sole carbon and nitrogen source (Fig. 2c). Possibly, one or several of these protein(s) are involved in the uptake of caprolactam.

Inside the cell caprolactam is most likely converted to 6ACA. This conversion might be dependent on a caprolactamase, catalyzing the opening of the lactam ring. Inspection of the caprolactam-induced proteins for a 
Table 2 General genomic features of various Pseudomonas species

\begin{tabular}{lllll}
\hline General features & Pj GO3 & Pb NFM421 & Pk 1855-344 & Pm SJ10 \\
\hline Size $(\mathrm{Mb})$ & 7.0 & 6.8 & 6.8 & 6.2 \\
GC $(\%)$ & 60.0 & 60.8 & 60.7 & 63.4 \\
CDS & 6231 & 6097 & 5856 & 5413 \\
Protein with predicted function $(\%)$ & 76.3 & & \\
\hline
\end{tabular}

The genome data are adopted from the original papers. These numbers may differ from numbers obtained with updated annotations

CDS coding sequences, Pb Pseudomonas brassicacearum NFM421 (Ortet et al. 2011), Pk Pseudomonas kilonensis 1855-344 (Eng et al. 2015), Pm P. mosselii SJ10 (Park et al. 2014)

lactamase-related protein resulted in the identification of two distinct polypeptides, ORF4270 and ORF4271. Database searches revealed identity to subunits A and B of the hydantoinase from Pseudomonas sp. (Table 3, respectively, 32 and $30 \%$ identity) and to the putative 5-oxoprolinase subunits A and B from Pseudomonas putida (OplA, 78\% identity and OplB, 86\% identity). The ORF4270 and ORF4271 encoded sequences also displayed weak similarity to eukaryotic 5-oxoprolinases which are known to catalyze the ATPdependent hydrolytic decyclization of 5-oxoproline, producing L-glutamate (Saccharomyces cerevisiae OXP1/YKL215c, 22 and 23\% identity, respectively) (Seddon et al. 1984). Since 5-oxoproline, hydantoin, and caprolactam share a lactam moiety, it is likely that proteins encoded by these two ORFs are involved in the caprolactamase reaction.

Further conversion of 6-ACA can proceed through deamination catalyzed by an aminotransferase, producing 6oxohexanoate. Inspection of the caprolactam-induced proteins resulted in the identification of a protein with homology to the Vibrio fluvialis $\omega$-amino acid aminotransferase (ORF4266, $43 \%$ identity). The well-characterized $V$. fluvialis enzyme catalyzes the pyruvate-dependent transamination of $\omega$-amino acids and other amines to aldehydes or ketones (Shin et al. 2003).
Fig. 2 Proteomic analysis of P. jessenii GO3 cells, obtained from two independent replicate cultures. A Number of $P$. jessenii proteins identified by mass spectrometry in replicate culture 1 (red) and replicate culture 2 (blue). The overlapping region represents the number of proteins identified in both experiments (purple). B Bar graph representing the total number of identified $P$. jessenii proteins (green), including several caprolactam-induced proteins (red) and several caprolactamrepressed proteins (blue). A protein was considered upregulated when the protein level in caprolactam-induced cells divided by the protein level in non-induced cells was larger than two; a protein was considered downregulated when this ratio was smaller than 0.5. C Bar graph representing the average $\mathrm{iBAQ}$ $\log 2$ protein amounts of the identified upregulated proteins in caprolactam-grown cells. For all these hits, the protein amounts in non-induced cells were below the level of detection (not depicted in this plot) (Color figure online)

\section{A}
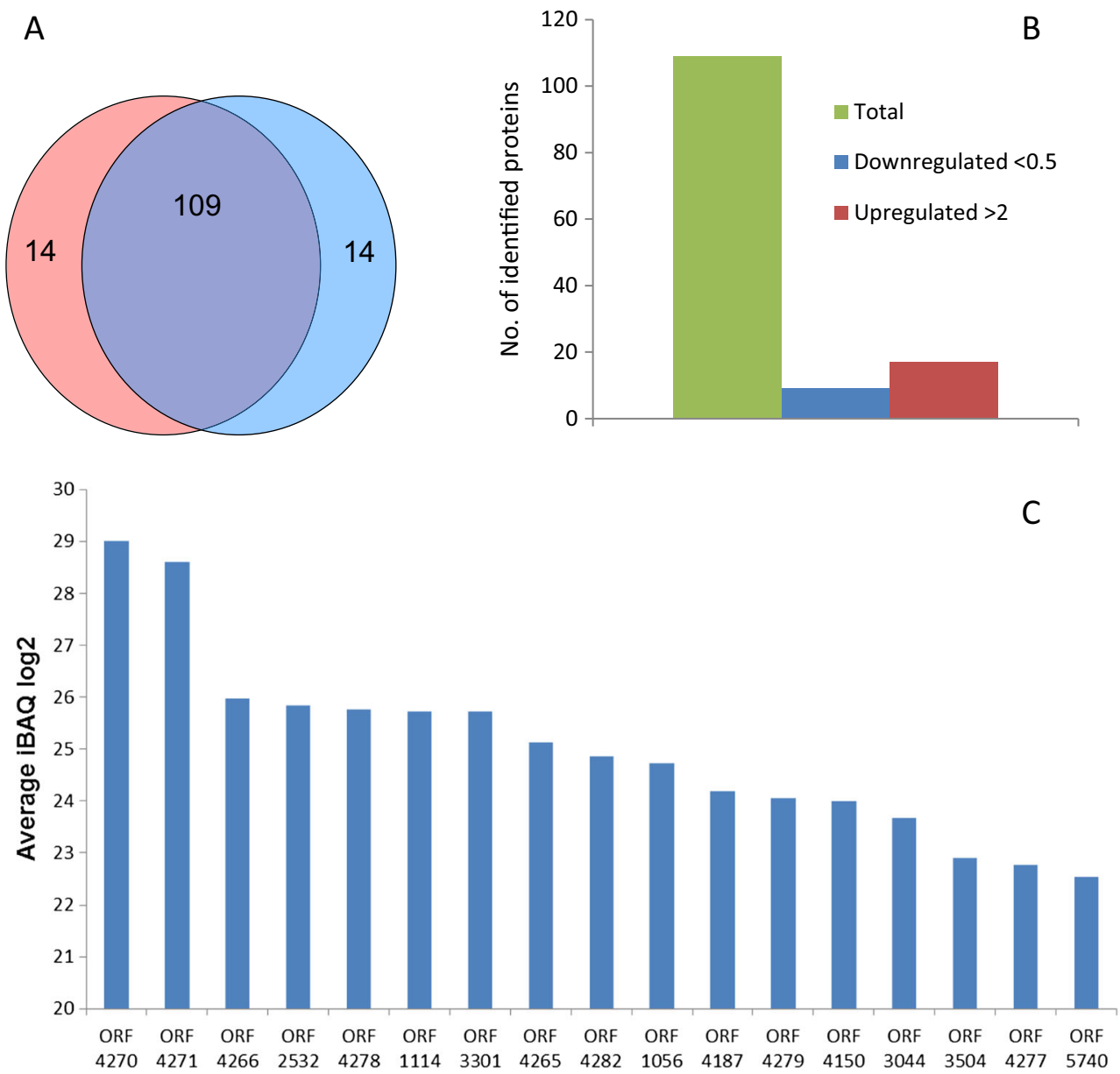
Table 3 Caprolactam-induced proteins

\begin{tabular}{|c|c|c|c|c|c|c|}
\hline Name & Contig & Size (bp) & Enzyme & $\begin{array}{l}\text { Seq. identity to known } \\
\text { proteins }(\% \text {, organism })\end{array}$ & EC number & $\begin{array}{l}\text { Accession } \\
\text { number }\end{array}$ \\
\hline 4265 & 5 & 1451 & Succinate-semialdehyde dehydrogenase & 81, E. coli & 1.2.1.24 & $3 \mathrm{JZ4}$ \\
\hline 4266 & 5 & 1367 & Omega aminotransferase & $43, V$. fluvialis & 2.6.1.18 & $3 \mathrm{NUI}$ \\
\hline 4270 & 5 & 2114 & Hydantoin utilization protein $\mathrm{A}$ & 32, Pseudomonas sp. & 3.5.2.- & Q01262 \\
\hline 4271 & 5 & 1745 & Hydantoin utilization protein B & 30, Pseudomonas sp. & 3.5.2.- & Q01262 \\
\hline 4277 & 5 & 1238 & Acetyl-CoA:oxalate CoA-transferase & 39, E. coli & 2.8.3.19 & 4HL6 \\
\hline 4278 & 5 & 1202 & Acetyl-CoA acetyltransferase & 41, Ralstonia eutropha & 2.3.1.9 & 4099 \\
\hline 4279 & 5 & 1541 & 3-Hydroxyacyl-CoA dehydrogenase & 39, R. eutropha & 1.1.1.35 & $4 \mathrm{PZC}$ \\
\hline 4282 & 5 & 1154 & Acyl-CoA dehydrogenase & 42, Thermus thermophilus & 1.3.99.2 & 2DVL \\
\hline 2532 & 28 & 1031 & $\mathrm{ABC}$ transporter, amino acid binding protein & 59, Brucella ovis & & $4 Z 9 N$ \\
\hline 3504 & 39 & 1922 & Serine protein kinase & 77, E. coli & 2.7.11.1 & P0ACY5 \\
\hline 4150 & 48 & 2147 & Fatty acid oxidation complex $\alpha$ subunit & 94, P. fragi & $\begin{array}{l}\text { 4.2.1.17 5.3.3.8 } \\
1.1 .1 .355 .1 .2 .3\end{array}$ & 1WDK \\
\hline 1056 & 157 & 1112 & $\mathrm{ABC}$ transporter, putrescine binding protein & $75, P$. aeruginosa & & 3ТTM \\
\hline 1114 & 161 & 1133 & $\begin{array}{l}\mathrm{ABC} \text { transporter, branched chain amino } \\
\text { acid binding protein }\end{array}$ & 51, Agrobacterium fabrum & & $3 \mathrm{IP} 5$ \\
\hline 3044 & 330 & 2549 & $\begin{array}{l}\mathrm{ABC} \text { transporter, Spermidine/putrescine } \\
\text { binding protein }\end{array}$ & 31, Streptococcus pneumoniae & & 4EQB \\
\hline 3301 & 363 & 344 & Putative enzyme of the cupin superfamily & 98, Pseudomonas sp. & & $\begin{array}{l}\text { WP } \\
084317822\end{array}$ \\
\hline 4187 & 485 & 1325 & Isocitrate lyase & 82, E. coli & 4.1.3.1 & $1 \mathrm{IGW}$ \\
\hline 5740 & 814 & 905 & Histone $\mathrm{H} 1$-like protein $\mathrm{HC} 2$ & 43, Chlamydia pneumoniae & & Q9Z8F9 \\
\hline
\end{tabular}

The product 6-oxohexanoate would then be converted to adipate. In Acinetobacter, this reaction is catalyzed by a 6oxohexanoate dehydrogenase (Iwaki et al. 1999). Among the caprolactam-induced proteins, one protein (ORF 4265) was identified with homology to the E. coli succinatesemialdehyde dehydrogenase. In E. coli, this enzyme converts succinate semialdehyde to succinate, which is part of the biodegradation of 4-aminobutyric acid (Donnelly and Cooper 1981). Since succinate-semialdehyde and 6-oxohexanoate are structurally similar, it is plausible that this enzyme is involved in the conversion of 6-oxohexanoate. Additionally, this protein has $38 \%$ sequence identity to the Acinetobacter 6-oxohexanoate dehydrogenase.

Finally, adipate most likely enters the $\beta$-oxidation pathway for degradation of fatty acids, which consists of multiple reactions (Janßen and Steinbüchel 2014). First adipate needs to be activated by CoA, resulting in adipyl-CoA. This reaction might be achieved by the caprolactam-induced protein with homology to the E. coli acetyl-CoA:oxalate CoA-transferase (ORF4277). In E. coli, this enzyme catalyzes the reversible conversion of oxalate and acetyl-CoA to oxalyl-CoA and acetate. Then, adipyl-CoA can be converted in a multistep process by means of an adipyl-CoA dehydrogenase (ORF4282), an enoyl-CoA hydratase, an 3-hydroxyadipyl-CoA dehydrogenase (ORF4279), and a 3-ketoadipyl-CoA thiolase (ORF4278). Homologs of all of these proteins were clearly induced in caprolactam-grown cells, where the enoyl-CoA hydratase function might be performed by a protein with homology to the Pseudomonas fragi fatty acid oxidation complex $\alpha$ subunit (ORF4150). In Pseudomonas, this complex catalyzes multiple reactions of the beta fatty acid oxidation, including the enoyl-CoA hydratase and the 3-hydroxyacylCoA dehydrogenase (Ishikawa et al. 2004).

\section{Gene organization}

The sequence information for most caprolactam-induced proteins was found on contig 5, a large segment of 40,376 bp containing 36 putative open reading frames (ORF4261 to ORF4296). The genetic context of this contig was analyzed using the RAST server. This revealed that contig 5 comprises two gene clusters involved in the caprolactam degradation.

The first gene cluster contains the genes putatively involved in the conversion of caprolactam to adipate, including both subunits of the proposed caprolactam-induced caprolactamase (ORF4270, ORF4271), the omega aminotransferase (ORF4266), and a 6-oxohexanoate dehydrogenase (ORF4265) (Fig. 4a). In between these genes, three other ORFs are located (Fig. 4a, Pj, in blue). BLAST searches revealed that these open reading frames encode proteins with high homology to the L-2-hydroxyglutarate oxidase LhgO of E. coli (ORF4267, 72\% identity), the starvation induced protein CsiD of P. putida (ORF4268, 75\%), and the transcriptional regulator CsiR from E. coli (ORF4269, 59\%). In E. coli, 
Fig. 3 Hypothetical pathway for the biodegradation of caprolactam in $P$. jessenii cells. A The conversion of caprolactam to adipate. B The first steps of the $\beta$ fatty acid degradation

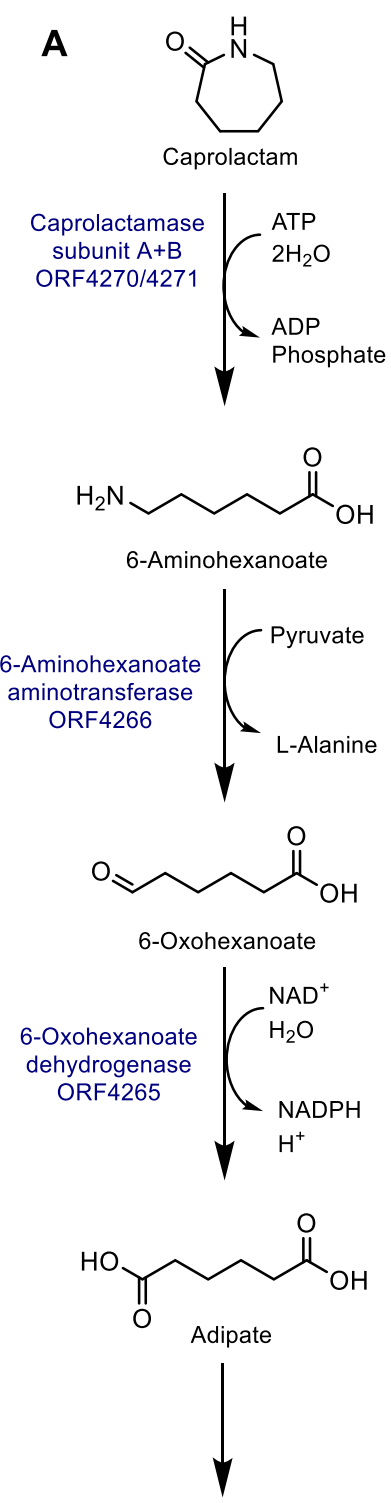

Fatty acid $\beta$-oxidation

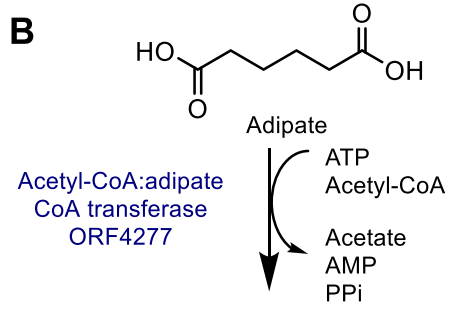<smiles>O=C(O)CCCCC(=O)OC(=O)OCc1ccccc1</smiles>

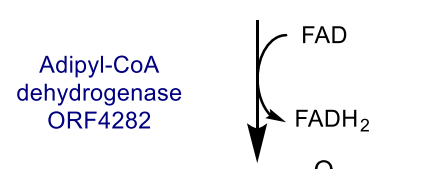<smiles>O=C(O)CC/C=C/C(=O)CCCCCCC(=O)O</smiles><smiles>CCC(C)C(C)CO</smiles>
ORF4280<smiles>O=C(O)CCC(O)CC(=O)CCOCCOC(=O)OCc1ccccc1</smiles>

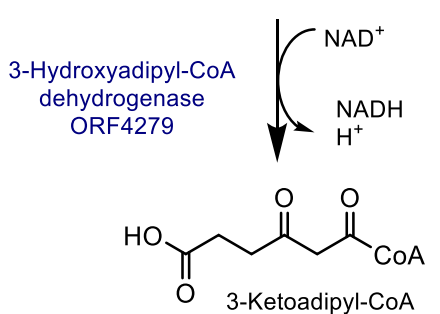
$\mathrm{H}^{+}$<smiles>CC(=O)OC(=O)OC(=O)CCC(=O)OC(=O)OC(C)=O</smiles>

these genes cluster together with gabD, gabT, and gabP involved in the conversion of $\gamma$-aminobutyrate to succinate. The gabD gene encodes a succinate-semialdehyde dehydrogenase (DH), gabT a $\gamma$-aminobutyrate aminotransferase (AT) and gabP a $\gamma$-aminobutyrate permease. GabT and GabD represent similar catalytic activities as the $P$. jessenii omega aminotransferase (ORF4266) and the 6-oxohexanoate dehydrogenase (ORF4265), respectively. Clear differences between both gene clusters include (1) the absence of a homolog of the $\gamma$ aminobutyrate permease gabP in $P$. jessenii, which might explain why $P$. jessenii is not able to grow on minimal medium supplemented with 6-ACA as sole nitrogen source; (2) the absence of a homolog of the caprolactamase genes ORF4270 and 4271 in E. coli, which appeared to be involved in the first step in caprolactam degradation in $P$. jessenii (Fig. 4a, genes labeled with*).

The second gene cluster includes genes involved in the fatty acid $\beta$-oxidation, including the caprolactam-induced acetyl-CoA:oxalate CoA-transferase (ORF4277), acetyl-CoA acetyltransferase (ORF4278), 3-hydroxyacyl-CoA dehydrogenase (ORF4279), and butyryl-CoA dehydrogenase (ORF4282). In between these genes, two more open reading 
frames are located which according to BLAST searches encode for proteins with high homology to an enoyl-CoA hydratase from Mus musculus (ORF4280, 47\% identity) and an IclR family transcriptional regulator from Pseudomonas testosteroni (ORF4281, 36\%). A similar gene cluster containing homologs of all six genes is present in the genome of other bacteria (e.g., Pseudomonas aeruginosa PAO1), suggesting a wider occurrence of adipate metabolism by the same pathway.

\section{ATP-dependent caprolactamase}

To confirm the presence of an ATP-dependent caprolactamase activity in $P$. jessenii, a cell-free extract of caprolactaminduced cells was prepared. Subsequently, the extract was incubated in the presence of caprolactam, ATP, and $\mathrm{MgCl}_{2}$, and the production of 6-ACA was examined by UPLC-MS. This revealed that caprolactam is indeed enzymatically converted to 6-ACA. When a similar assay was performed using the cell-free extract of glucose-grown $P$. jessenii cells, no conversion of caprolactam to 6-ACA was detected. This confirmed that the caprolactamase activity present in $P$. jessenii cells is induced during growth on caprolactam. Additionally, to study the ATP dependence of the putative caprolactamase in $P$. jessenii cells, cell-free extracts of caprolactam-grown cells containing $\mathrm{MgCl}_{2}$ were prepared and tested for the formation of 6-ACA in the absence of ATP. No 6-ACA formation was detected, demonstrating that ATP indeed is required for the enzymatic hydrolyses of caprolactam to 6-ACA.

To confirm the role of the putative caprolactamase (ORF4270, ORF4271) in the conversion of caprolactam, the genes were expressed in $E$. coli $\mathrm{C} 41$. To express both subunits (CapA, CapB) simultaneously, the entire operon including the 36-bp intergenic region (Fig. 4) was cloned under control of a single T7 promoter. Expression in E. coli resulted in the highlevel production of two proteins of the expected size, of which approximately $60 \%$ was present in the soluble fraction. UPLC-MS analysis was performed to detect the formation of 6-ACA in a mixture containing caprolactam, ATP, $\mathrm{MgCl}_{2}$, and $E$. coli cell-free extract. Time course analyses demonstrated that 6-ACA levels increased and caprolactam levels decreased in time. A specific activity of $0.14 \mathrm{U} / \mathrm{mg}$ was calculated for the $E$. coli cell-free extract (Fig. 5). In reaction mixtures containing caprolactam, ATP, $\mathrm{MgCl}_{2}$, and $E$. coli extract from cells not producing the caprolactamase, no detectable 6ACA was observed even after $3 \mathrm{~h}$ of incubation. Thus, the caprolactamase activity detected in the induced $E$. coli (pETOP) extract originates from the expressed $\alpha$ and $\beta$ subunits of the caprolactamase. Since the sequence of the $\alpha$ and $\beta$ subunits showed homology to enzymes annotated as 5oxoprolinase, reaction mixtures containing 5-oxoproline, ATP, $\mathrm{MgCl}_{2}$, and $E$. coli cell-free extract were tested for the production of glutamate. UPLC-MS analyses demonstrated no detectable glutamate even after $3 \mathrm{~h}$ of incubation. This revealed that 5-oxoproline is not a substrate for the identified $P$. jessenii caprolactamase.

\section{Characterization of the omega aminotransferase}

Most omega aminotransferases are PLP-fold type I enzymes that catalyze the transfer of an amino group from a $\beta-, \gamma-$ or other $\omega$-amino acid or an amine to pyruvate or $\alpha$ ketoglutarate (Schiroli and Peracchi 2015). In order to confirm the presence of 6-ACA $\omega$-aminotransferase activity in $P$. jessenii GO3, a protein extract of caprolactam-induced cells was prepared and incubated with 6-ACA and pyruvate or $\alpha$ ketoglutarate, and levels of 6-ACA and produced alanine or glutamate were determined using OPA derivatization and HPLC. This revealed that caprolactam was indeed enzymatically converted with pyruvate as the amino acceptor. In the absence of pyruvate, no conversion of 6-ACA was detected. When a similar assay was performed using cell-free extract of glucose-grown $P$. jessenii cells, no conversion of 6-ACA or pyruvate was found. This confirmed the presence of a caprolactam-inducible $\omega$-transaminase activity in $P$. jessenii GO3 cells.

To establish if this ORF4266-encoded putative $\omega$-amino acid aminotransferase (PjAT) is responsible for the conversion of 6-ACA, activity assays were performed using $E$. coliexpressed PjAT. Since E. coli contains multiple aminotransferases, PjAT was equipped with a C-terminal His6-tag, and the enzyme was purified using a Ni-NTA resin. This yielded ca. 30-35 mg purified enzyme/L of culture. The activity of the enzyme was examined in both directions, so with 6oxohexanoate or with 6-ACA as substrate, together with Lalanine or pyruvate as amino acceptor. Activities were obtained by coupling the reaction to that of alanine dehydrogenase and following production or consumption of NADH spectrophotometry at $340 \mathrm{~nm}$. This revealed a specific activity of $0.2 \mathrm{U} / \mathrm{mg}$ using 6-ACA and pyruvate as the substrates and an activity of $4.5 \mathrm{U} / \mathrm{mg}$ using 5-oxohexanoate and alanine as the substrates. These activities would suffice to enable strain GO3 to use caprolactam as a nitrogen source for growth.

\section{Discussion}

In this work, we explored the caprolactam degradation pathway in the bacterium $P$. jessenii strain GO3. Previous studies suggested an overall catabolic pathway for caprolactam metabolism, but the enzymes catalyzing the first two steps, i.e., conversion of caprolactam to 6-oxohexanoate, remained unknown. Using proteomic studies, we identified an ATPdependent lactamase involved in the conversion of caprolactam to 6-ACA and an $\omega$-aminotransferase responsible for the subsequent conversion of 6-ACA to 6-oxohexanoate. 


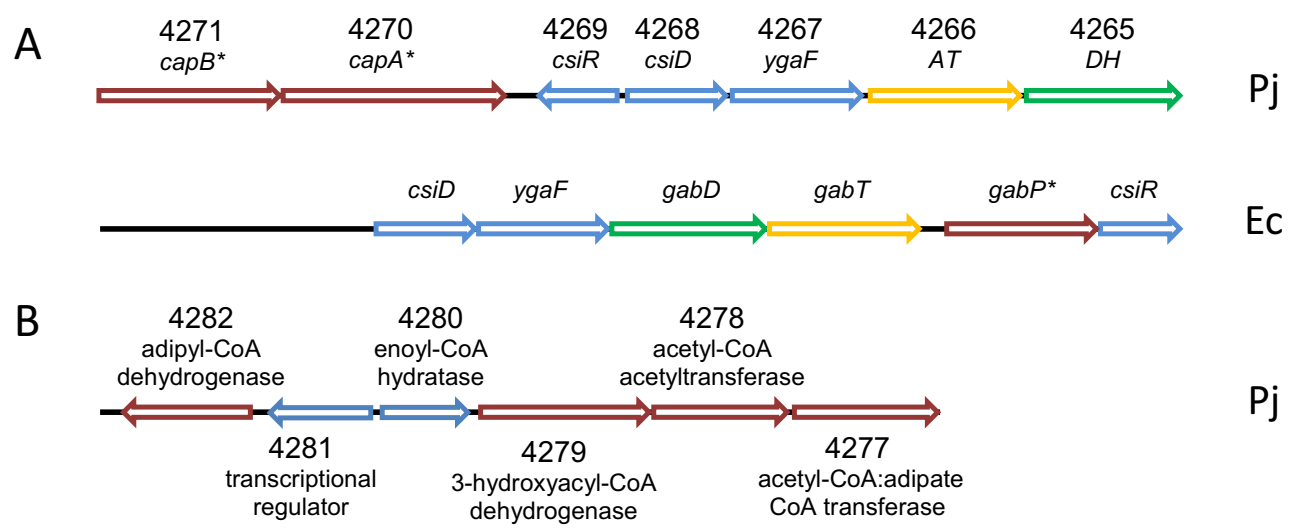

Fig. 4 Schematic representation of the gene organization of contig 5, containing most of the caprolactam-induced genes, analyzed using the RAST server. a Gene cluster comprising the genes putatively involved in the conversion of caprolactam to adipate in P. jessenii $(\mathrm{Pj})$ and a similar gene cluster with the genes involved in the conversion of $\gamma$-aminobutyrate in $E$. coli $(\mathrm{Ec})$. Genes marked with an asterisk indicate clear differences

Additionally, we identified various other enzymes and genes putatively involved in the caprolactam catabolic pathway.

The ATP-dependent lactamase catalyzing caprolactam ring opening was identified by proteomic studies, sequence comparison to known proteins with lactamase activity, and functional expression in E. coli. Sequence comparison indicated similarity to proteins annotated as 5-oxoprolinase or hydantoinase. Oxoprolinases catalyze the ATP-dependent hydrolysis of 5-oxoproline to glutamate (EC 3.5.2.9). The sequence of only four oxoprolinases with confirmed activity has been reported, including the enzymes from rat and cow (Ye et al. 1996; Watanabe et al. 2004), S. cerevisiae (Kumar and Bachhawat 2010), and the human enzyme. The latter can harbor mutations of medical relevance (Calpena et al. 2015). The eukaryotic 5-oxoprolinases are homodimers with subunits of approximately $137 \mathrm{kDa}$, whereas the P. putida 5oxoprolinase, of which the sequence is not reported, consists of two different subunits of approximately 75 and $63 \mathrm{kDa}$

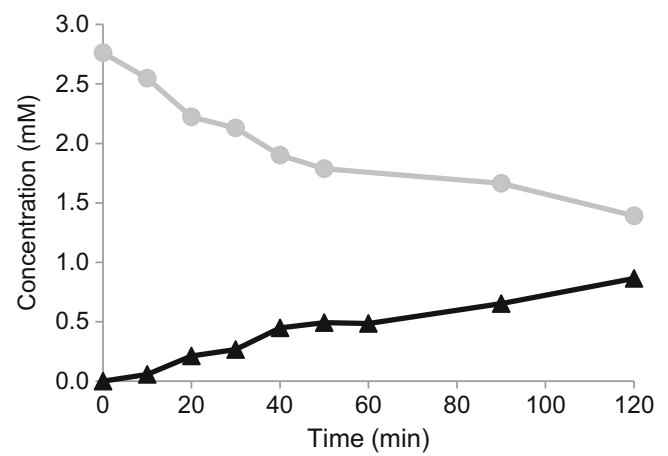

Fig. 5 UPLC-MS analyses monitoring the formation of 6-ACA (black line, triangles) and the degradation of caprolactam (grey line, closed circles). The reaction mixtures contained $2 \mathrm{mM}$ caprolactam, $5 \mathrm{mM}$ ATP, $10 \mathrm{mM} \mathrm{MgCl}$, and $75 \mu \mathrm{g} / \mathrm{mL}$ cell-free extract, in $50 \mathrm{mM}$ ammonium bicarbonate, $\mathrm{pH} 8.5$ between the $P$. jessenii and $E$. coli gene clusters. b Gene cluster comprising the genes putatively involved in the fatty acid $\beta$ degradation of adipate. Genes represented in blue: $P$. jessenii genes encoding proteins that were not significantly upregulated (Color figure online)

(Seddon and Meister 1986; Li et al. 1988). Subunit A, which is homologous to the $\mathrm{N}$-terminal part of the $137 \mathrm{kDa}$ subunit of the eukaryotic enzymes, catalyzes the phosphorylation of enzyme-bound 5-oxoproline, whereas subunit $\mathrm{B}$, which is homologous to the $\mathrm{C}$-terminal part of eukaryotic oxoprolinase, is required for hydrolysis of the phosphorylated hydroxypyrrole. Other enzymes with significant sequence similarity to the caprolactamase are the ATP-dependent hydantoinases. Only the N-terminal sequences of the two subunits of the enzyme isolated from P. putida 77 have been reported (Ogawa et al. 1995), but BLAST searches allow retrieval of complete sequences from Marinobacterium profundum (WP_067296627.1 and WP_067296623.1). Sequence alignments show that in addition to the A and B subunits of the bacterial oxoprolinases mentioned previously, also the $\mathrm{A}$ and B subunits of these putative hydantoinases and the $\alpha$ and $\beta$ subunits of caprolactamase described here correspond to the $\mathrm{N}$-terminal part and C-terminal part, respectively, of the eukaryotic oxoprolinases. All these ATP-dependent hydrolases belong to InterPro families IPR002821 and IPR003692. We demonstrated the ATP dependence of the caprolactamase activity using enzyme expressed in E. coli. Within the families, there are clear differences. For example, the substrate range of the $P$. jessenii caprolactamase lacks 5-oxoprolinase activity. It seems possible that many bacterial genes annotated in GenBank as 5-oxoprolinase actually are (capro)lactamase genes or cyclic dipeptide hydrolase genes, since there is a higher sequence similarity to the CapA and CapB ORFs than to confirmed oxoprolinases.

Based on sequence and structural analysis, these lactamases can be further grouped with the ATP-dependent carboxylases/lactamase superfamily, which includes carboxylases acting on acetone and acetophenone (Weidenweber et al. 2017). The structure of the acetophenone carboxylase 
from Aromatoleum aromaticum EbN1 was recently solved (pdb 519w), revealing its quaternary structure as $\left(\alpha \alpha^{\prime} \beta \gamma\right)_{2}$. Sequence motifs indicative of ATP binding are conserved between the $\alpha$ subunit of the carboxylase and the $\alpha$ subunit of caprolactamase (ORF 4270), and the $\beta$ subunit of the carboxylase is homologous to the $\beta$ subunit of caprolactamase (ORF 4271). Thus, the elucidation of the caprolactam catabolism described here adds a new member to this diverse group of ATP-dependent hydrolytic enzymes. By similarity to oxoprolinase and hydantoinase, caprolactam hydrolysis by the caprolactamase is expected to proceed by phosphorylation of the enol (lactim) tautomer mediated by the $\alpha$ subunit, followed by its hydrolysis with a role for the $\beta$ subunit. Structures of lactamases that would provide detailed insight are lacking, however.

The 6-aminohexanoate aminotransferase (PjAT) catalyzing the second step in caprolactam catabolism was also identified by proteomic studies, sequence similarities, and functional overexpression in E. coli. BLAST searches using the protein sequence of the PjAT demonstrated relatedness to the foldtype I PLP enzymes, more in particular to the subgroup II aminotransferases, which are now often grouped as class III aminotransferases (Schiroli and Peracchi 2015; SteffenMunsberg et al. 2015). These enzymes catalyze conversion of $\omega$-amino acids to aldehydes (EC 2.6.1.18). In vitro characterization of PjAT confirmed the expected deamination of 6ACA to 6-oxohexanoate. The enzyme was also active in the reverse reaction: L-alanine-dependent amination of 6aminohexanoate. This conversion is of potential interest for a biosynthetic 6 -ACA production pathway that was recently engineered into E. coli (Turk et al. 2015). Comparison with the $V$. fluvialis aminotransferase, which is the closest wellstudied homolog, revealed conservation of several residues important for proper activity (PDB code 4E3Q; (Midelfort et al. 2013)). The lysine required for the formation of the internal aldimine (Schiff base) with the PLP cofactor is present at a conserved position. Further work on the biocatalytic and structural properties of the enzyme is ongoing. The PjAT aminotransferase has $27.3 \%$ pairwise sequence identity with the NylD1 aminotransferase recently described in the nylon oligomer degrader Arthrobacter sp. KI72 (Takehara et al. 2018). The closest homolog of the latter enzyme in the $P$. jessenii genome is ORF2380 (48.6\% pairwise identify), but an upregulation of this protein was not detected by proteomic analysis of caprolactam-grown $P$. jessenii cultures.

Previously, the full genome of $P$. mosselii, another caprolactam degrading organism isolated from wastewater of a nylon producing industrial complex in Korea, was sequenced by Park and coworkers (Park et al. 2014). Interestingly, BLAST searches using the sequences of the genes that were found here to be involved in caprolactam degradation against the full $P$. mosselii genome sequence revealed genes with high similarity to these proteins (aminotransferase 100\%, CapA 99.6\%, and CapB 99.3\% sequence identity). This suggests the same caprolactam degradation pathways in both Pseudomonas species. Additionally, BLAST searches against the non-redundant protein database revealed highly similar open reading frames in annotated sequences of various other Pseudomonas strains, indicating that the ability to hydrolyze lactams or cyclic peptides may not be unusual in Pseudomonas. Other nylon byproducts that can be degraded by microorganisms include 6ACA dimers, cyclic dimers, and oligomers. Metabolism is dependent on hydrolases, such as NylA, NylB, and NylC, which have different specificities (Negoro 2000). NylA catalyzes the hydrolysis of 6-ACA cyclic dimer, resulting in the formation of the 6-ACA dimer, which can be converted by NylB, generating 6-ACA. NylC catalyzes the hydrolysis of 6ACA oligomers. BLAST searches using Flavobacterium sp. NylA, B, and C revealed that $P$. jessenii contains homologs of NylA and NylB, but not of NylC, suggesting the absence of a complete pathway for metabolism of 6-ACA polymers.

Acknowledgements The authors acknowledge M. Schürman and S. Turk (DSM, The Netherlands) for their support and helpful discussions and T. Tiemersma-Wegman for assistance with the MS analysis.

Author's contributions MO performed the proteomic and genomic studies. MO and CP performed bioinformatic analysis and expression experiments. MO, CP, and DJ wrote the paper.

Funding information This research was supported financially by the Dutch Ministry of Economic Affairs and BE-Basic (www.be-basic.org), a public/private research organization.

\section{Compliance with ethical standards}

Ethical statement This article does not contain any studies with human participants or animals performed by any of the authors.

Conflict of interest The authors declare that they have no conflict of interest.

Open Access This article is distributed under the terms of the Creative Commons Attribution 4.0 International License (http:// creativecommons.org/licenses/by/4.0/), which permits unrestricted use, distribution, and reproduction in any medium, provided you give appropriate credit to the original author(s) and the source, provide a link to the Creative Commons license, and indicate if changes were made.

\section{References}

Ahmed SA, Esaki N, Soda K (1982) Purification and properties of $\alpha$ amino- $\epsilon$-caprolactam racemase from Achromobacter obae. FEBS Lett 150:370-374

Ahmed SA, Esaki N, Tanaka H, Soda K (1986) Mechanism of $\alpha$-amino$\varepsilon$-caprolactam racemase reaction. Biochemistry 25:385-388

Aziz RK, Bartels D, Best AA, DeJongh M, Disz T, Edwards RA, Formsma K, Gerdes S, Glass EM, Kubal M, Meyer F, Olsen GJ, 
Olson R, Osterman AL, Overbeek RA, MacNeil LK, Paarmann D, Paczian T, Parrello B, Pusch GD, Reich C, Stevens R, Vassieva O, Vonstein V, Wilke A, Zagnitko O (2008) The RAST server: rapid annotations using subsystems technology. BMC Genomics 9:75

Baxi N, Shah A (2002) $\varepsilon$-Caprolactam-degradation by Alcaligenes faecalis for bioremediation of wastewater of a nylon- 6 production plant. Biotechnol Lett 24:1177-1180

Boronin A, Naumova R, Grishchenkov V, Ilijinskaya O (1984) Plasmids specifying $\varepsilon$-caprolactam degradation in Pseudomonas strains. FEMS Microbiol Lett 22:167-170

Calpena E, Deshpande AA, Yap S, Kumar A, Manning NJ, Bachhawat AK, Espinós C (2015) New insights into the genetics of 5oxoprolinase deficiency and further evidence that it is a benign biochemical condition. Eur J Pediatr 174:407-411

Caspi R, Altman T, Billington R, Dreher K, Foerster H, Fulcher CA, Holland TA, Keseler IM, Kothari A, Kubo A, Krummenacker M, Latendresse M, Mueller LA, Ong Q, Paley S, Subhraveti P, Weaver DS, Weerasinghe D, Zhang P, Karp PD (2014) The MetaCyc database of metabolic pathways and enzymes and the BioCyc collection of pathway/genome databases. Nucleic Acids Res 42:D459-D471

Chun J, Lee JH, Jung Y, Kim M, Kim S, Kim BK, Lim YW (2007) EzTaxon: a web-based tool for the identification of prokaryotes based on 16S ribosomal RNA gene sequences. Int J Syst Evol Microbiol 57:2259-2261

Donnelly MI, Cooper RA (1981) Succinic semialdehyde dehydrogenases of Escherichia coli. Eur J Biochem 113:555-561

Eng WW, Gan HM, Gan HY, Hudson AO, Savka MA (2015) Wholegenome sequence and annotation of octopine-utilizing Pseudomonas kilonensis (previously P. fluorescens) strain 1855344. Genome Announc 3:e00463-e00415

Esikova T, Ponamoreva O, Baskunov B, Taran S, Boronin A (2012) Transformation of low-molecular linear caprolactam oligomers by caprolactam-degrading bacteria. J Chem Technol Biotechnol 87: 1284-1290

Fabre B, Lambour T, Bouyssié D, Menneteau T, Monsarrat B, BurletSchiltz O, Bousquet-Dubouch M (2014) Comparison of label-free quantification methods for the determination of protein complexes subunits stoichiometry. EuPA Open Proteom 4:82-86

Fortmann L, Rosenberg A (1984) Fate of $\epsilon$-caprolactam in the aquatic environment. Chemosphere 13:53-65

Fukumura T, Talbot G, Misono H, Teramura Y, Kato K, Soda K (1978) Purification and properties of a novel enzyme, L- $\alpha$-amino- $\epsilon-$ caprolactamase from Cryptococcus laurentii. FEBS Lett 89:298300

Gabor EM, De Vries EJ, Janssen DB (2004) Construction, characterization, and use of small-insert gene banks of DNA isolated from soil and enrichment cultures for the recovery of novel amidases. Environ Microbiol 6:948-958

Ishikawa M, Tsuchiya D, Oyama T, Tsunaka Y, Morikawa K (2004) Structural basis for channelling mechanism of a fatty acid $\beta$ oxidation multienzyme complex. EMBO J 23:2745-2754

Iwaki H, Hasegawa Y, Teraoka M, Tokuyama T, Bergeron H, Lau PC (1999) Identification of a transcriptional activator (ChnR) and a 6oxohexanoate dehydrogenase $(\mathrm{ChnE})$ in the cyclohexanol catabolic pathway in Acinetobacter sp. strain NCIMB 9871 and localization of the genes that encode them. Appl Environ Microbiol 65:51585162

Janßen HJ, Steinbüchel A (2014) Fatty acid synthesis in Escherichia coli and its applications towards the production of fatty acid based biofuels. Biotechnol Biofuels 7:1

Kalinová JP, Tříska J, Vrchotová N, Moos M (2014) Verification of presence of caprolactam in sprouted achenes of Fagopyrumesculentum Moench and its influence on plant phenolic compound content. Food Chem 157:380-384
Kalinová JP, Tř́ska J, Vrchotová N, Novák J (2016) Uptake of caprolactam and its influence on growth and oxygen production of Desmodesmusquadricauda algae. Environ Pollut 213:518-523

Kulkarni RS, Kanekar PP (1998) Bioremediation of $\varepsilon$-caprolactam from Nylon-6 waste water by use of Pseudomonas aeruginosa MCM B-407. Curr Microbiol 37:191-194

Kumar A, Bachhawat AK (2010) OXP1/YKL215c encodes an ATPdependent 5-oxoprolinase in Saccharomyces cerevisiae: functional characterization, domain structure and identification of actin-like ATP-binding motifs in eukaryotic 5-oxoprolinases. FEMS Yeast Res 10:394-401

Li LY, Seddon AP, Meister A (1988) Interaction of the protein components of 5-oxoprolinase. Substrate-dependent enzyme complex formation. J Biol Chem 263:6495-6501

Midelfort KS, Kumar R, Han S, Karmilowicz MJ, McConnell K, Gehlhaar DK, Mistry A, Chang JS, Anderson M, Villalobos A, Minshull J, Govindarajan S, Wong JW (2013) Redesigning and characterizing the substrate specificity and activity of Vibrio fluvialis aminotransferase for the synthesis of imagabalin. Protein Eng Des Sel 26:25-33

Negoro S (2000) Biodegradation of nylon oligomers. Appl Microbiol Biotechnol 54:461-466

Ogawa J, Kim JM, Nirdnoy W, Amano Y, Yamada H, Shimizu S (1995) Purification and characterization of an ATP-dependent amidohydrolase, N-methylhydantoin amidohydrolase, from Pseudomonas putida 77. Eur J Biochem 229:284-290

Ortet P, Barakat M, Lalaouna D, Fochesato S, Barbe V, Vacherie B, Santaella C, Heulin T, Achouak W (2011) Complete genome sequence of a beneficial plant root-associated bacterium, Pseudomonas brassicacearum. J Bacteriol 193:3146-3111

Palacio CM, Crismaru CG, Bartsch S, Navickas V, Ditrich K, Breuer M, Abu R, Woodley J, Baldenius K, Wu B (2016) Enzymatic network for production of ether amines from alcohols. Biotechnol Bioeng 113:1853-1861

Park G, Chu J, Hong S, Kwak Y, Khan AR, Jung BK, Ullah I, Shin J (2014) Complete genome sequence of the caprolactam-degrading bacterium Pseudomonas mosselii SJ10 isolated from wastewater of a nylon 6 production plant. J Biotechnol 192:263-264

Payoungkiattikun W, Okazaki S, Ina A, Aran H, Asano Y (2017) Characterization of an $\alpha$-amino- $\varepsilon$-caprolactam racemase with broad substrate specificity from Citreicella $\mathrm{sp}$. SE45. J Ind Microbiol Biotechnol 44:677-685

Poelarends GJ, Wilkens M, Larkin MJ, van Elsas JD, Janssen DB (1998) Degradation of 1, 3-dichloropropene by Pseudomonas cichorii 170. Appl Environ Microbiol 64:2931-2936

Rajoo S, Ahn JO, Lee HW, Jung JK (2013) Isolation and characterization of a novel $\varepsilon$-caprolactam-degrading microbe, Acinetobactercalcoaceticus, from industrial wastewater by chemostat-enrichment. Biotechnol Lett 35:2069-2072

Sambrook J, Russell DW, Russell DW (2001) Molecular cloning: a laboratory manual, 3rd edn. Cold Spring Harbor Laboratory Press, New York

Schiroli D, Peracchi A (2015) A subfamily of PLP-dependent enzymes specialized in handling terminal amines. Biochim Biophys Acta 1854:1200-1211

Seddon AP, Meister A (1986) Trapping of an intermediate in the reaction catalyzed by 5-oxoprolinase. J Biol Chem 261:11538-11543

Seddon AP, Li LY, Meister A (1984) Resolution of 5-oxo-L-prolinase into a 5-oxo-L-proline-dependent ATPase and a coupling protein. J Biol Chem 259:8091-8094

Sheldon T (1989) Chromosomal damage induced by caprolactam in human lymphocytes. Mutat Res 224:325-327

Shin J, Yun H, Jang J, Park I, Kim B (2003) Purification, characterization, and molecular cloning of a novel amine: pyruvate transaminase from Vibrio fluvialis JS17. Appl Microbiol Biotechnol 61:463-471 
Steffen-Munsberg F, Vickers C, Kohls H, Land H, Mallin H, Nobili A, Skalden L, van den Bergh T, Joosten H, Berglund P (2015) Bioinformatic analysis of a PLP-dependent enzyme superfamily suitable for biocatalytic applications. Biotechnol Adv 33: 566-604

Takehara I, Fujii T, Tanimoto Y, Kato D, Takeo M, Negoro S (2018) Metabolic pathway of 6-aminohexanoate in the nylon oligomer-degrading bacterium Arthrobacter sp. KI72: identification of the enzymes responsible for the conversion of 6aminohexanoate to adipate. Appl Microbiol Biotechnol 102: 801-814

Turk SC, Kloosterman WP, Ninaber DK, Kolen KP, Knutova J, Suir E, Schürmann M, Raemakers-Franken PC, Müller M, de Wildeman SM, Raamsdonk LM, van der Pol R, Wu L, Temudo MF, van der Hoeven RA, Akeroyd M, van der Stoel RE, Noorman HJ, Bovenberg RA, Trefzer AC 2016. Metabolic engineering toward sustainable production of nylon-6. ACS Synth Biol 5:65-73

van der Wal L, Demmers JAA (2015) Quantitative mass spectrometrybased proteomics. In: Magdeldin S (ed) Recent advances in proteomics research. InTech, Rijeka. https://doi.org/10.5772/61756 Available from: https://www.intechopen.com/books/recentadvances-in-proteomics-research/quantitative-mass-spectrometrybased-proteomics
Vizcaíno JA, Csordas A, del-Toro N, Dianes JA, Griss J, Lavidas I, Mayer G, Perez-Riverol Y, Reisinger F, Ternent T, Xu QW, Wang R, Hermjakob H (2016) 2016 update of the PRIDE database and its related tools. Nucleic Acids Res 44:D447-456

Vogel E (1989) Caprolactam induces genetic alterations in early germ cell stages and in somatic tissue of D. melanogaster. Mutat Res 224: 339-342

Wasinger VC, Zeng M, Yau Y (2013) Current status and advances in quantitative proteomic mass spectrometry. Int J Proteomics 2013: 180605

Watanabe T, Abe K, Ishikawa H, Iijima Y (2004) Bovine 5-oxo-Lprolinase: simple assay method, purification, cDNA cloning, and detection of mRNA in the coronary artery. Biol Pharm Bull 27: 288-294

Weidenweber S, Schuhle K, Demmer U, Warkentin E, Ermler U, Heider J (2017) Structure of the acetophenone carboxylase core complex: prototype of a new class of ATP-dependent carboxylases/hydrolases. Sci Rep 7:39674

Ye GJ, Breslow E, Meister A (1996) The amino acid sequence of rat kidney 5-oxo-L-prolinase determined by cDNA cloning. J Biol Chem 271:32293-32300 